\title{
Technology and Institutions in neo-Schumpeterian and Original Institutional Thinking
}

\author{
Iciar Dominguez Lacasa *
}

\section{Zusammenfassung}

Ziel dieses Beitrags ist es, die Wechselwirkungen zwischen Technologie und Institutionen in sozioökonomischen Prozessen aus Sicht der Original Institutional Economics (OIE) und der neo-Schumpeterianischen Ökonomik (NSE) zu analysieren. Insbesondere werden Affinitäten und Divergenzen beider ökonomischen Denkschulen identifiziert, um Impulse für deren Zusammenarbeit zu setzen. Beide Theoriestränge heben die Bedeutung von Wissen und Institutionen für die wirtschaftliche Entwicklung hervor. Ganz konkret lassen sich die Gemeinsamkeiten beider Denkschulen in drei Bereichen erkennen: (i) in der Bedeutung von Wissen für die sozioökonomische Entwicklung, (ii) in dem handlungsbezogenen Charakter der Technologie, die von Institutionen geprägt wird, und (iii) in der Handlungsfähigkeit von Akteuren im technologischen Wandel. In Anbetracht der Gemeinsamkeiten könnten beide Denkrichtungen von Synergien profitieren. Die neo-Schumpeterianische Konzeptualisierung der wirtschaftlichen Entwicklung könnte um die Berücksichtigung des Wertesystems und der Machtstruktur erweitert werden. Werte und Macht spielen aus Sicht der OIE eine Schlüsselrolle für die Verbreitung (bzw. Beibehaltung) von Wissen und Technologie. Beide Aspekte werden von OIE operationalisiert und können der Weiterentwicklung der Modellierung von Selektionsmechanismen in neo-Schumpeterianischen Ansätzen dienen, um die Pfade der wirtschaftlichen Entwicklung zu erklären.

\section{Abstract}

The aim of this inquiry is to deepen our understanding of the interactions between knowledge, technologies and institutions in socio-economic process by considering the affinities and divergences of Original Institutional Economics (OIE) and neo-Schumpeterian economics (NSE). Both strands of evolutionary economic thought recognize the importance of knowledge for human progress and the role of institutions in molding this process. OIE and NSE share a common perspective in what concerns (i) the role of knowledge for socio-economic change, (ii) the behavioral dimension of technology molded by institutions, and (iii) the role of purposeful evaluation in processes of institutional and technological change. Considering these commonalities, both strands of thinking could benefit from "joining forces". Firstly, the conceptualization of how knowledge and technologies drive human progress from a neo-Schumpeterian perspective could very much benefit from the consideration of the value system and the power structure sustaining it as put forward by OIE. Values and power appear as key determinants channeling (or retaining) knowledge towards human progress. Moreover, the role of the value system as suggested by OIE could be operationalized and further developed to explain paths of socio-economic development drawing on the conceptualization of "selection mechanisms" as put forward by neo-Schumpeterian models.

\section{Introduction}

The body of economic literature exploring processes of technological change and its influence on economic progress and social change has largely recognized the need to properly account for the interactions between technologies and institutions. Specially two schools of economic thought are aware of these interactions: neo-Schumpeterian Economics (NSE) and Original Institutional Economics (OIE). The aim of this inquiry is to find complementarities between these two strands of evolutionary economic research to improve our understanding on how knowledge and technologies trigger human progress. Previous research has already considered the commonalities and differences of both strands of research (Hodgson 2007, Frigato \& Santos-Arteaga 2012). Our goal is to identify a potential research path for both schools to join forces. Rather than reviewing the body of research of both evolu- tionary schools of economic thought, we will focus on contributions of two contemporary exponents developing the theoretical grounds of both strands of research in what concerns the conceptualization of technologies and institutions and their role in socio-economic change : Richard Nelson and Paul Bush. Both authors view the socio-economic system as a structure of coordinated behavior for the application and diffusion of knowledge and information as described by Metcalfe 
(2014), where innovations face evaluation processes generated by prevailing orders (Metcalfe 2014: 26). This common general view, together with their explicit consideration of the interaction of technologies and institutions for socio-economic change make them especially interesting for the purpose of this paper. Richard Nelson is among the most influential exponents of the neo-Schumpeterian strand of economic research. Together with Sidney Winter he has concentrated on the study of economic growth and differences of growth and innovation rates across industries. Their seminal contribution (Nelson \& Winter 1982) stressed the role of technological change as the motor of economic growth. Moreover, Richard Nelson has largely acknowledged the role of institutions in processes of technological change. His conceptualization of institutions and their interaction with technology has developed in the last 30 years. Even though the collaborative work between Richard Nelson and Sidney Winter published in 1982 did not explicitly aim at bringing institutions into the study of technological change and economic growth, their analysis had strong institutional aspects in the Veblenian sense of "habits of thought". Nelson (2002) recognizes this connection in the concept of "routines". Hodgson (2007) has also stressed the institutional aspects of Nelsons work. More recently, also together with Bhaven N. Sampat (Nelson \& Sampat 2001, Nelson 2002, 2005, 2008) he developed the concept of "social technologies" and explicitly called for the need to bring institutions into the analysis of technological change and economic growth. Interestingly, even though he refers to Veblen and the American Institutionalist School in his more recent work (Nelson 2002: 19, Nelson 2005: 144; Nelson 2008: 2), he does not deepen into important developments in Original Institutional Thinking (Hayden 2006). Paul Bush, has largelly contributed to Classical Institutional thinking in economics. As a school of thought in economics and social science, Classical Institutional Inquiry is frequently noted as the Original Institutional Economics, and is distinguished by the acronym OIE. This school adopts fundamental precepts that differentiate it from what is known as New Institutional Economics, a school of thought stemming from ideas advanced by Ronald Coase and Douglass North. Classical Institutional Inquiry stems from seminal ideas advanced by Veblen. Research of William Waller (1982) suggests that Veblen's understanding of an institution changed and evolved over the years of his active inquiry. In the Veblen literature we find a proclivity for scholars to borrow an understanding from his Absentee Ownership and Business Enterprise in Recent Times [1923]. Here, Veblen (1923: 101) teaches us that an institution is "of the nature of a usage which has become axiomatic and indispensible by habituation and general acceptance." Moreover, in his writings Veblen stresses the role of technology for social change (Veblen 1904, 1914). Scholars have intensively discussed Veblen's concepts of "institution" and "technology" and the implications of different interpretations for the analysis of socio-economic change (Hodgson 2004, Waller 1982). Paul Bush (1983, 1987) draws on the extensions and refinements of Veblen's disciples to put forward a theory where institutional change is mainly driven by knowledge growth and technological change. In a more recent contribution, Bush and Tool (2001: 197) define their perspective as "neoinstitutionalist", based on the integration of Veblenian analysis with John Dewey's philosophy as Clarence E. Ayres' developed it.

The paper discusses their conceptualization of technologies and institutions, identifies commonalities and suggests a research path for OIE and NSE to join forces.

\section{Institutions and Technologies in neo-Schumpeterian Thinking}

To discuss how technologies and institutions are conceptualized in neo-Schumpeterian Thinking we focus on the work of Richard Nelson. His integration of technologies, institutions and economic growth has developed in the last 30 years. Together with Sidney Winter he published An Evolutionary Theory of Economic Change in 1982 inspiring a community of researchers contributing to the development of what is called neo-Schumpeterian eco- nomics. Their work was a tentative of explaining how the strategies of heterogeneous firms in the pursuit of competitive advantage are significant determinants of the rate and direction of technological change and economic growth. For this purpose they introduce search and selection mechanisms to explain changes in the rate and direction of technological change (Nelson \& Winter 1982). In 1982 Nelson and Winter introduced two key elements in their analysis of economic growth: (i) an industry as a population of heterogeneous firms with dynamic behavior and (ii) an unchanging selection environment prescribing which firms grow and survive. In Nelson and Winter's view, firm behavior and the selection environment entail clear institutional aspects.

\section{Firm behavior}

In what concerns firm behavior, even though their vision of the economy considers different types of organizations involved in technical advance, profit-oriented firms aiming at improving its position vis-à-vis their competitors are the key units of specification in the modeling exercises of Nelson and Winter (1982). Nelson and Winter (1982: 250, 263) recognize that different types of organizations do research and development (R\&D): universities, firms, the government. Their objectives in what concerns investment in $R \& D$ differ. Moreover, their decision rules are responsive to variables that guide the achievement of these different purposes. Nelson and Winter opt explicitly for the use of the term "firm" to refer to all these different organizations (Nelson \& Winter 1982: 264).

Drawing on organizational and behavioral concepts developed by March, Simon and Cyert the main assumptions of Nelson and Winter regarding the behavior of the firm deal with the question of why firms do what they do, or in other words, which are the factors shaping firms' decision-making. The answer to this questions draws on institutions. More specifically, to them the possible behavior of a firm is determined by its so called "routines". Routines may be considered as collective rules or procedures that programme the behavior of firms 
and change their characteristics over time. They store essential information, which is remembered (or transferred) between individuals. Rather than the result of optimization problems, firms' strategies in taking management and technological decisions are shaped by these behavioral and cognitive regularities (routines). ${ }^{1}$ Agency though can influence the evolution and implementation of routines. In other words, firms are considered to have a criteria to evaluate potential changes in routines. In most models this criteria is anticipated profit (Nelson \& Winter 1982: 18). With routine guided search firms explore alternative technological directions for more effective means of production.

\section{Technologies}

Firms are the careers of technology. To introduce technical advance in their formal models, Nelson and Winter (1982: Chapter 9) conceptualized firms and technological change at first in a highly simplified way: technological change is the result of routine guided search by firms and improves productivity of capital. Successful innovations increase productivity and tend to enhance the profitability of a firm. Accordingly, firms aim at developing better technologies (increases in productivity) to produce more effectively and compete in a selection environment.

\section{The Selection Environment} and Technological Change

In what concerns the selection environment, Nelson and Winter's (1982) models conceptualize a market with production from firms and a demand from consumers. The market represents an unchanging selection mechanism, which applies to less profitable firms, or, in other words, to those firms who are not able to keep up with the pace of technological progress of their competitors. Firm's profitability in the market determines whether firms expand or contract to develop the power structure of the market in terms of firms ` size and market shares.

Nelson and Winter are aware of the simplification of their models and go further to develop in a descriptive way (ii) the process of search for technologies and (iii) alternative selection environments to the market (Nelson \& Winter 1982: Chapter 11). These considerations introduced in chapter 11 of their seminal work draw on previous publications (Nelson \& Winter 1977) and have been further developed in later contributions (Nelson 2003, 2002).

In what concerns technological change, firms explore alternative directions in which to search for novel technical solutions or improvements. However, this choice is not random. Guided by routines technicians in their problem-solving activities develop beliefs about what is worth attempting, or to which extent certain improvements may be feasible or not.

Technological advance involves search and evaluation of possible technological options according to economic parameters (such as unit production costs given demand and factor supply conditions, pay off) and technical dimensions specific to the particular technologies (such as size, chemical composition, etc.) (Nelson \& Winter 1982: 248). Given the heterogeneity of organizations driving technical advance, the evaluation of possible technological options will differ among agents given their heterogeneous ends of investing in R\&D. Organizations adopt or not a technical improvement depending on the benefits and costs, on the profitability. The term "profitable" indicates the value of the technical advance "in the eyes of the firm, without implying that the objectives are monetary profit rather than something else" (Nelson \& Winter 1982: 264). The dimensions of this "profit" may vary across organizations and the way organization weighed economic and technical criteria vary across types of organizations. This range of possible directions of technological development based on the assessments of what is technologically feasible and worth attempting has been called by Nelson and Winter a "technological regime" (Nelson \& Winter 1977, Nelson \& Winter 1982: 258). Underlying these trajectories, there is a "body of knowledge held by techni- cians, engineers and scientists involved in the relevant inventive activity" (Nelson \& Winter 1982: 261).

The complexity of this selection environment has been tackled by Nelson and his colleagues in a number of contributions. In their early models Nelson and Winter relate explicitly the selection environment to the institutional structure shaping innovation processes. To them, the concept of selection environment allows for considering the institutional complexity and variety in the economy (Nelson \& Winter 1977: 70). The selection environment determines the evaluation of inventions among users (i.e. fitness) and captures the incentives for firms to engage in research and development or in solving-problem processes. Dosi and Nelson (1994) stress that the competitiveness of firms in the selection environment may depend on diverse (sometimes even conflicting) criteria. The mechanisms through which selection occur are very complex: Dosi and Nelson point out the possible endogeneity of the selection criteria themselves in the economic system (Dosi \& Nelson 1994: 156). Moreover, evaluation and incentives vary among economic sectors and activities. This institutional diversity of the real economy has been stressed more recently by Nelson (2003). To Nelson "the economy is the term used to denote and focus attention on the activities of the community that use scarce resources to achieve human purposes" (Nelson 2003: 706). Under this perspective, economic enquiry needs to consider the whole range of governing structures of economic activity: "market, government, neighborhood groups, voluntary associations, clubs, etc." (Nelson 2003: 706). The challenge for economic analysis is to study the nature of evaluation and diffusion of technical advance in different institutional structures (market and non-market selection environments) (Nelson \& Winter 1977: 71, Nelson 1988: 268).

In more recent contributions, Nelson further develops on the integration of technologies, institutions and economic growth (Nelson 2005, 2008). For this purpose, he defines the "economic

1 As pointed out by Becker (2004) the concept of "routine" as Nelson and Winter proposed it is not associated with the every-day meaning of the term in many languages. Variation and change are phenomena that are not in opposition to the concept of routines. 
activity" as the basic unit of analysis to conceptualize technologies and institutions. Building on the concept of "routine" and on its role in deploying economic activities he differs between "social technologies", "physical technologies" and "institutions". To Nelson "social technologies" are coordinated behavior of actors involved "in doing something useful", social technologies refer to "the way work is divided and coordinated" (Nelson \& Sampat 2001: 44, Nelson 2008: 3). Social technologies complement physical technologies in economic activities. He points out that the "productivity or effectiveness of an activity" is determined by both: social and physical technologies (Nelson 2008: 3). In this framework, Institutions are "structures that define or mold the way economic agents interact to get things done" (Nelson 2005: 153) or "structures and forces that mold and hold in place prevalent social technologies" (Nelson 2008: 3). From this view, institutions framing and supporting social technologies refer to a broad set of things from law to organizations including market and non-market structures. Nelson stresses that social and physical technologies interact and change in the process of economic growth. New physical technologies give rise to changes in social technologies (changes in behavior to pursuit economic activities) and in the institutions supporting them. Social technologies and institutions are however more difficult to mold, control and replicate than physical technologies. A main difference between both types of technologies lies on the "scientific" understanding bearing both types of technologies. To Nelson, there is a much larger body of scientific knowledge and cumulative learning related to physical technologies. Moreover, the establishment and diffusion of social technologies "can be driven by fad or ideology" (Nelson 2008: 9). Given these differences, Nelson's final interest lies on the identification of institutions required for economic progress. Interestingly, he largely acknowledges the role of human purpose and beliefs in determining what is feasible and appropriate for the selection of institutions and in the determination of the institutions that survive (Nelson 2008: 7). Nelson does not elaborate the se- lection processes of institutions. As we will see bellow, these aspects of social evolution have been largely developed by OIE.

\section{Technologies and Institutions in Original Institutional Thinking}

In the Veblenian tradition and drawing largely on Foster (1981), Paul Bush (1987: 1076) takes a holistic view of society to study socio-economic evolution. Bush defines an institution as "a set of socially prescribed patterns of correlated behavior". A behavioral pattern involves "two behaviors (or activities) and a value that acts as the standard by which the behaviors are correlated" (Bush \& Tool 2001: 206, see also Bush 1987: 1077). We understand correlated behavior (or activity) as aligned behavior among human beings. Coordinated collective activity according to social prescriptions. This behavioral alignment in collective action builds the institutional structure of the community. The institutional structure is hence a set of "patterns of behavior" established and generally accepted in the community. Even though Bush acknowledges the possibility of randomness in human behavior, he stresses that, especially in problem-solving (purposive) behavior, social prescriptions organize human activities. Most importantly, the correlation (alignment) of behavior among human beings rests on values.

\section{Values and changes in the value structure}

A key element in the contributions of Paul Bush is the explicit consideration of the value system as a main building block of the institutional structure (Bush 1987). Most importantly, the analysis of the evolution of economic institutions in the society rests on analyzing the changes in the value structure (Bush \& Tool 2001: 204). To Bush, values are the "socially accepted standards of judgment for human action." Human activity involves hence "valuation" (the use of a value as standard of judgment in specific situations such as establishing an education system, producing and providing goods and services). Interestingly for Bush, values are "the outcome of conscious choices" and institutional change a "discre- tionary process" (Bush 1987: 1077). In a contribution to a volume edited by Kurt Dopfer (Dopfer 2001), Bush and Tool briefly discusse how values are used in community's decision processes and how they undergo a selection process to warrant their function in guiding collective action. They briefly present the concept of "value judgment" as "the selection of a value as an appropriate standard of judgment" (Bush \& Tool 2001: 202-203).

Building upon what Veblen (1904) elaborated at length as a discrepancy between the industrial needs of the community and the pecuniary needs of the corporation, Bush discerns between two types of values: "instrumental values" and "ceremonial values." For Bush (1983: 37, 1987: 1079-1080) "instrumental values" on the one hand are standards of judgment that develop from the application of knowledge, tools and skills in problem-solving processes. Most importantly, they are "self-correcting" standards of judgment since they are the result of knowledge accumulation in problem-solving processes to serve the community. These values are assessed according to the implications of using them to guarantee efficiency in problem solving. On the other hand, "ceremonial values" offer criteria for discerning invidious distinctions and for establishing a power structure in the community. Research of Bush (1987: 1085) suggests that validation of ceremonial values (i.e. the assessment of the appropriateness of values as standards of judgment) is not found in knowledge but rather in tradition, and with the formulation of beliefs and ideologies. While instrumental values are self-correcting and change with the accumulation of knowledge, ceremonial values are ingrained in the community's established proper way of doing things. The value system can display ceremonial or instrumental dominance depending on whether ceremonial or instrumental values mainly correlate behavior in the community.

These values used for aligning behavior determine whether institutions manifest themselves ceremonial or instrumental characteristics. Under this logic Bush develops his interpretation 
of the Veblenian dichotomy. Ceremonially warranted patterns of behavior establish institutions for defining status, a power structure and differential privileges in the community. Instrumentally warranted patterns of behavior establish institutions for efficiently solving problems in the community and to guarantee its continuity (Bush 1987: 1082-1085). Sustainable socioeconomic progress draws hence on the establishment of instrumentally warranted patterns of behaviour to solve societal challenges. On institutions with a instrumental function. Whether they are able to embody human action and social processes depends, from Bush perspective, on the value structure of the society.

\section{Technologies}

Technologies in Bush's view are esential for institutional change and socioeconomic progress (Bush 1987: 1089). Bush's concept of technology goes beyond the physical tools, machines and assembly lines (Bush 1987, 1983, Bush \& Tool 2001). Technology is defined very broadly as a "form of behavior" that involves the skills and knowledge "upon which the community depends in the problem-solving processes" (Bush \& Tool 2001: 205). The increase of knowledge in the community brings about technology. Changes in behavior in problem-solving processes (behavior with instrumental aims) bring about a challenge for the institutional structure since in collective action individual behavior needs to align with prevailing structures of behavior (or activities). The extent to which new technology is able to become fully embodied in behavioral patterns depends on the prevailing value system. What Bush teaches us is that technology and instrumentally warranted patterns of behavior (institutions with instrumental function) are fundamentally and categorically different. The application of knowledge to solve a problem translates into a behavior with instrumental aims (i.e. a technology). Nonetheless, it does not automatically entail instrumentally warranted patterns of behavior in collective action to solve the problem. This new behavior (Technology) needs to be correlated within the institutional structure with other be- haviors (or activities). Under conditions that the value system suffers under ceremonial dominance (mainly ceremonial values correlate behavior in the community) technologies will be ingrained in institutions protecting vested interests rather than in institutions solving societal problems. This institutional structure may allow for incremental technological innovations, however, it deprives the community of the full potential for technologies to effectively address a pressing social problem.

\section{Institutional Change}

Bush (1987: 1101-1102) develops the concepts of "Institutional Adjustment" and "Progressive Institutional Change" to describe the changes needed in the institutional space for a community to fully exploit its technological possibilities. In a situation of ceremonial dominance these changes refer to the looseness or even displacement of ceremonial constraints by instrumental values through dynamics of "cumulative causation". Incremental technological innovation triggers learning and finally a modification in the value structure of the community which reflects institutional change. The interaction of technologies and institutions works through knowledge generation and changes in collective action. Institutional change results when collective action triggers changes in the value system for new technologies to develop and diffuse.

\section{Discussion}

After reviewing selected research of Richard Nelson on the integration of technologies, institutions and economic growth and having discussed Paul D. Bush's theory of institutional change, we now turn to highlight the common aspects and potential paths of research to identify the variables channeling knowledge and technological change towards human progress.

Indeed, both strands of research acknowledge the importance of technological advance for human progress in a system of coordinated collective action. Given this common overarching view of socio-economic change, both OIE and NSE share a perspective in what concerns (i) the role of knowl- edge for technological change, (ii) the behavioral dimension of technology molded by an institutional structure, and (iii) the role purposeful evaluation in processes of institutional and technological change.

In what concerns the role of knowledge for technological change, the contributions considered recognize that technology is more than machines and tools. It involves knowledge and a behavior for solving problems. In the Nelson and Winter models, economic agents engage in research activities to develop technologies. Moreover, the possible directions of technological development (the technological regimes) lie on the knowledge and skills of technicians and engineers involved. Even though in the simulation models of Nelson and Winter (1982) technical advance is highly simplified as an increase in firm 's productivity, technologies develop along trajectories through problem-solving processes and evaluation mechanisms. Also Nelson's concept of social technologies explicitly involves knowledge embodied in coordinated collective behavior. On the other hand, to Paul D. Bush the growth of the knowledge fund of the community is an essential process underlying technological development. Paul D. Bush concept of technology is explicitly a form of behavior that involves the skills and knowledge to be applied in problem-solving processes.

As to institutions, in both strands institutions mold human behavior (also in problem-solving activities). Bush explicitly takes a Veblenian perspective to conceptualize institutions as socially prescribed patterns of human behavior in collective action. In simple words, to Bush institutions are collective action coordinated by established values. Institutional change implies changes in the value system. In the neo-Schumpeterian contributions considered, the role of institutions is at first less explicit. Nonetheless, institutions mold different dimensions of the economy. Firstly, Nelson and Winter conceptualize firm's strategies for triggering technological advance in terms of rules or procedures that programme the behavior of firms. These rules are called "routines". This concept recalls to the 
idea of "habits of thought" among members of a technological community in a Veblenian sense. Routines molde firm 's behavior and with it technical advance. This connection with Veblen in the conceptualization of firms strategies and decision-making processes has been recognized by Nelson (2002). Nelson's concept of social technologies (Nelson 2008) and his concept of institutions as organizations, laws, rules, etc. that support them has again strong veblenian influences and explicitly recognizes that habituation and social acceptance are essential elements of human agency. Interestingly, institutions also appear in the collaborative work of Nelson and Winter (1982) in the conceptualization of the selection environment. The selection environment challenging firms to develop technical advances to grow and survive represents the complex institutional structure determining technological change. Interestingly, Nelson largely acknowledges the role of human purpose and beliefs in determining what is feasible and appropriate for the selection of institutions and in the determination of the institutions that survive. However, he does not elaborate on the selection processes of institutions and the role of the value system in this concern.

In what concerns the role of purposeful evaluation in processes of technological change, both strands of research consider that agents are actively involved in evaluation processes that determine the path of technological development and (in the case of Paul D. Bush) the institutional structure and its dynamics. This aspect of the research relates to the extent to which the value system (or criteria for decision-making and problem-solving processes) is included in the analysis of technological and institutional change. In the case of Bush the value system and, to a lesser extent, the purposeful evaluations by agents are essential and well developed parts of his theory of institutional change. He distinguishes between ceremonial and instrumental values. To him, values correlating (technological) behavior determine the ultimate function of technologies in collective action; they offer a framework to qualify technological development according to its final aims and the extent to which technological development triggers human progress. Instrumental values evaluate whether technologies are employed in an efficient way in problem solving in respect to what is technologically feasible. Ceremonial values, on the other hand, provide the terms according to which privileges should be granted to the members of the community. They determine the status and power structure within the community. Values are the core of the institutional structure and can change. Most importantly, values are the result of purposeful behavior and have been established by the economic agents. From this perspective, agents influence the institutional structure in the establishment of a value system and mold its changes. At the same time, the institutional structure molds human behavior.

Nelson also refers explicitly to values and selection criteria both within firms and in the selection environment challenging firms to grow and survive. In what concerns evaluation processes within firms, organizations adopt (or not) a technical improvement depending on its profitability. For Nelson and Winter the term "profitable" indicates the value of the technical advance in the eyes of the firm. Even though Nelson and Winter recognize that the term does not imply that the objectives of technical advance are monetary profit, in their models profit is model as pecuniary variable that determines the growth of firms and a power structure within the industry. With respect to evaluation in the selection environment, again Nelson and Winter, and specially Nelson in his younger contributions, recognize the need of considering different types of selection environments for firms and technologies beyond the market institution based on monetary profit as incentive for technical advance. However, their modeling exercises introduce market environments as unchanging selection mechanisms and do not develop formal alternatives. All in all, even though the theory put forward by Nelson acknowledges the need of going beyond market mechanisms and monetary profitability as incentive for technological development, his modeling exercises together with Sidney Winter do not consider changes in the selection environment or alternative ways of organizing markets as to account for changes in the selection environments.

To us, NSE theorizing about technological change and economic growth could very much benefit from the conceptualization of the value system as in Bush's theory of institutional change. The value system in Bush's theory can improve the concept of institutional structure (selection environment) in NSE. In his theory of institutional change Bush allows for different incentives or values that can trigger investments in research and development: instrumental and ceremonial values. This differentiation allows for the consideration of different evaluation standards and moreover, it brings into the analysis the influence that the power structure of the industry can have on the definition of the selection environment. The power structure is relevant since, in certain situations, the growth of knowledge does not guarantee that available (or feasible) technologies are developed to effectively address pressing social problems. With an institutional structure (selection environment) dominated by ceremonial values to preserve a given power structure, available knowledge for technological development may be applied for technical advance only to the point that the power structure of the industry remains unchanged. Investment in $R \& D$ and technical advance are then molded by institutions generating social costs. As an example, in a monopoly market structure, profit seeking as motivation for investment in research and development allows for technological advance along technological paths that preserve the monopoly power and have negative welfare consequences. In this situation, Bush's theory of institutional change considers changes in the value system (dislocation of ceremonial values granting monopoly power by instrumental values granting use of knowledge for solving problems effectively) as a chance for exploiting alternative existing technological possibilities. For NSE thinking this means the need for dynamic selection environments with varying selection criteria that guarantee the instrumental use of knowledge to reduce social costs. NSE 
and OIE could join forces to develop models of industry evolution and socio-economic change considering the value system. These models could consider interactions between technological change, industry power structures and valuation mechanisms of the selection environment (institutional structure). In the presence of social costs, the consideration of changes in the selection environment (i.e. different market organizations or different cost accounting mechanisms) can guarantee a selection environment channeling investments in technologies reducing social costs rather investment in technologies preserving a given power structure of the industry.

\section{REFERENCES}

Becker MC (2004) Organizational routines: a review of the literature. Industrial and Corporate Change 13(4):643-678

Bush PD (1983) An Exploration of the Structural Characteristics of a Veblen-Ayres-Foster Defined Institutional Domain. Journal of Economic Issues 27(1):35-66.

Bush PD (1987) The Theory of Institutional Change. Journal of Economic Issues 11(3):1075-1116

Bush P, Tool M (2001) The Evolutionary Principles of American Neoinstitutional Economics. In: Dopfer K (ed) Evolutionary Economics: Program and Scope, Springer Netherlands, ISBN 978-94-010-0648-4, pp. 195-229

Dopfer, K (2001) Evolutionary Economics: Program and Scope, Springer Netherlands. ISBN 978-94-010-0648-4

Dosi G, Nelson RR (1994) An introduction to evolutionary theories in economics. Journal of Evolutionary Economics 4:153-172

Foster JF (1981) The Effect of Technology on Institutions. Journal of Economic Issues 15(4): 907-913

Frigato P, Santos-Arteaga Fl (2012) Planned obsolescence and the manufacture of doubt: on social costs and the evolutionary theory of the firm. In: Wolfram E, Frigato P, Paolo R (eds) Social Costs Today, Routledge, Abingdon, pp. 73-95

Hayden FG (2006) Technology, Institutions, and Economic Growth by Richard R. Nelson. Journal of Economic Issues. 40(4):1177-1181

Hodgson GM (2004) The Evolution of Institutional Economics: Agency, Structure and Darwinism in American Institutionalism. Routledge, London and New York.

Hodgson GM (2007) The 2007 Veblen-Commons Award Recipient: Richard R. Nelson. Journal of Economic Issues 41(2):311

Metcalfe S (2014) Capitalism and Evolution. Journal of Evolutionary Economics 24:11-34

Nelson RR (1988) National systems of innovation and institutions supporting technical change in the United States. In: Dosi G, Freeman C, Nelson R, Silverberg G, Soete L (eds) Technical Change and Economic Theory, Printer, London, pp. 309-329

Nelson RR, Sampat BN (2001) Making sense of institutions as a factor shaping economic performance. Journal of Economic Behavior \& Organization 44(1):31-54

Nelson RR (2002) Technology, institutions and innovationsystems. Research Policy 31:265-272

Nelson RR (2003) On the Complexities and Limits of Market Organization. Review of International Political Economy 10(4):697-710

Nelson RR (2005) Technology, Institutions, and Economic Growth. Harvard University Press, London. ISBN: 9780674019164

Nelson RR (2008) What enables rapid economic progress: What are the needed institutions? Research Policy 37:1-11

Nelson R, Winter SG (1977) In search of a useful theory of innovation. Research Policy 6(1):33-76

Nelson RR, Winter SG (1982) An evolutionary theory of economic change. The Belknap Press of Harvard University Press, Cambridge. ISBN: 0-674-27228-5

Veblen T (1904) [2005] The Theory of the Business Enterprise. Cossimo Classics, New York.

Veblen T (1914) [1990] The Instinct of Workmanship and the State of the Industrial Arts. Transaction publishers, New Brunswick.
Veblen T (1923) [1996] Absentee Ownership: business enterprise in recent times: the Case of America. Transaction publishers, New Brunswick.

Waller WT (1982) The Evolution of the Veblenian Dichotomy: Veblen, Hamilton, Ayres, and Foster. Journal of Economic Issues: 757-771

\section{AUTHOR}

Prof. Dr. rer. pol. habil. Iciar Dominguez Lacasa Technische Hochschule Wildau

E-Mail for correspondence:

dominguez_lacasa@th-wildau.de

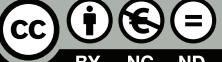

